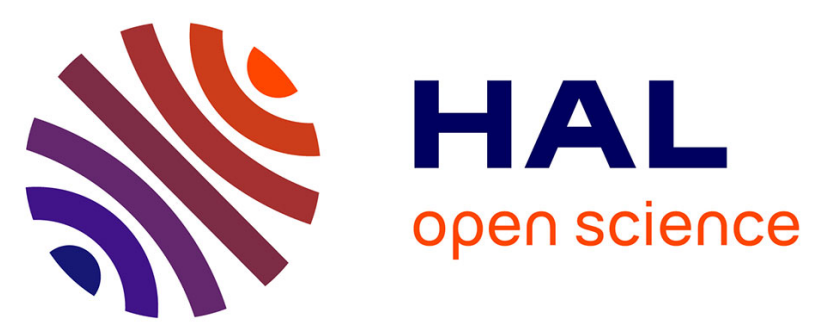

\title{
Enantioenriched Methylene-Bridged Benzazocanes Synthesis by Organocatalytic and Superacid Activations
}

Rodolphe Beaud, Bastien Michelet, Yasmin Reviriot, Agnès Martin-Mingot, Jean Rodriguez, Damien Bonne, Sébastien Thibaudeau

\section{- To cite this version:}

Rodolphe Beaud, Bastien Michelet, Yasmin Reviriot, Agnès Martin-Mingot, Jean Rodriguez, et al.. Enantioenriched Methylene-Bridged Benzazocanes Synthesis by Organocatalytic and Superacid Activations. Angewandte Chemie International Edition, 2020, 59 (3), pp.1279-1285. 10.1002/anie.201912043 . hal-02436747

\section{HAL Id: hal-02436747 https://hal.science/hal-02436747}

Submitted on 13 Jan 2020

HAL is a multi-disciplinary open access archive for the deposit and dissemination of scientific research documents, whether they are published or not. The documents may come from teaching and research institutions in France or abroad, or from public or private research centers.
L'archive ouverte pluridisciplinaire HAL, est destinée au dépôt et à la diffusion de documents scientifiques de niveau recherche, publiés ou non, émanant des établissements d'enseignement et de recherche français ou étrangers, des laboratoires publics ou privés. 


\title{
Enantioenriched Methylene-Bridged Benzazocanes Synthesis by Organocatalytic and Superacid Activations
}

\author{
Rodolphe Beaud, Bastien Michelet, Yasmin Reviriot, Agnès Martin-Mingot, Jean Rodriguez,* \\ Damien Bonne, * and Sébastien Thibaudeau*
}

\begin{abstract}
Achieving in a straightforward way the synthesis of enantioenriched elaborated three-dimensional molecules related to bioactive natural products remains a long-standing quest in organic synthesis. Enantioselective organocatalysis potentially offers a unique opportunity to solve this problem, especially when combined with complementary modes of activation. Here, we report the sequential association of organocatalytic and superacid activations of simple linear achiral readily available precursors to promote the formation of unique highly elaborated chiral methylene-bridged benzazocanes exhibiting three to five fully-controlled stereocenters. This peculiar backbone, difficult to assemble by standard synthetic approaches, is closely related to bioactive natural and synthetic morphinans and benzomorphans. The formation of a highly reactive chiral 7-membered ring $\mathrm{N}$-acyl iminium superelectrophilic ion, evidenced by low-temperature in situ NMR experiments, triggers a challenging stereoselective Friedel-Crafts-type cyclization.
\end{abstract}

\section{Introduction}

One essential objective in chemical synthesis is to convert readily available and inexpensive starting materials to complex functional molecules with a perfect stereocontrol. ${ }^{[1]}$ Excellence and innovation in this field are critical to success in all phases of drug discovery and development ${ }^{[2]}$ expanding the diversity of molecules for modulating biological targets. $^{[3,4]}$ Conversely, the best chance to break new grounds is through diversity. Enantioselective organocatalysis offers powerful solutions to these endeavors. ${ }^{[5]}$ It greatly enhances the synthetic toolbox by complementing metal-based and enzymatic approaches. ${ }^{[6]}$ Reaching high level of efficiency, ${ }^{[7]}$ demonstrated in the total synthesis of biologically active compounds, ${ }^{[8]}$ organocatalysis has been recently successfully merged with metal catalysts, ${ }^{[9]}$ chiral anions, ${ }^{[10,11]}$ photochem-

[*] Dr. R. Beaud, Y. Reviriot, Prof. J. Rodriguez, Dr. D. Bonne Aix Marseille Université, CNRS, Centrale Marseille, iSm2 Marseille (France)

E-mail: jean.rodriguez@univ-amu.fr damien.bonne@univ-amu.fr

Dr. B. Michelet, Dr. A. Martin-Mingot, Prof. S. Thibaudeau Université de Poitiers, UMR-CNRS 7285, IC2MP, Equipe Synthèse Organique "Superacid Group"

4 rue Michel Brunet, TSA 51106, 86073 Poitiers Cedex 9 (France)

E-mail: sebastien.thibaudeau@univ-poitiers.fr ical reactivity, ${ }^{[12-14]}$ biocatalysis ${ }^{[15,16]}$ and acid activation. ${ }^{[17,18]}$ Among acid activations, superacid chemistry ${ }^{[19]}$ has grown over the last years, ${ }^{[20]}$ especially through the exploitation of highly reactive in situ protosolvated electrophiles (superelectrophiles), as first suggested by Olah. ${ }^{[21]}$ Using superelectrophilic activation, reactions that cannot occur in conventional media can be used to generate innovative organic compounds, ${ }^{[22]}$ as pioneered by the essential use of $\mathrm{HF} / \mathrm{SbF}_{5}$ for the synthesis of the anti-cancer agent Javlor. ${ }^{[23]}$ Here we show that associating enantioselective organocatalysis with superacid activation results in an innovative synthetic strategy to generate otherwise inaccessible enantioenriched molecular frameworks related to bioactive series.

It has been recently assessed that some areas of research in synthetic methods would have critical impact in the pharmaceutical industry. Among them, the concise synthesis of highly functionalized, constrained chiral bicyclic amines ${ }^{[24]}$ has been identified as an high potential area ${ }^{[25]}$ to develop new drugs. ${ }^{[26]}$ Especially, benzomorphans and related bridged benzazocanes, which mimic morphinan natural products, are involved in the treatment of neurological disorders, ${ }^{[27]}$ as exemplified by the development of the promising racemic sigma 2 receptor agonist UKH-1114 exhibiting antineuropathic pain effect (Figure $1 \mathrm{~A}) .{ }^{[28]}$ However, the direct synthetic access to medium-sized heterocycles from simple acyclic substrates still constitutes a challenge in modern synthetic organic chemistry. The eight-membered ring series is particularly difficult to prepare because of negative enthalpic and entropic factors. ${ }^{[29]}$ In consequence, the enantioselective synthesis of functionalized methylene-bridged benzazocane derivatives is limited to one example reported to date (Figure 1B). ${ }^{[30,31]}$ Recently, we studied the organocatalyzed enantioselective synthesis of aza-oxa-bicyclo[3.2.1] octanes. $^{[32]}$ Based on this work, we envisioned that starting from simple achiral $\alpha$-ketoamides $\mathbf{1}$ and enals $\mathbf{2}$, enantioenriched oxabridged azepanes $\mathbf{3}$ could be temporarily generated and subsequently exploited to access stereoselectively the targeted methanobenzazocanes 4. This strategy relies on the superacid-promoted formation of a highly reactive $N$-acyl iminium ion $\mathbf{A}$, which could counterbalance the unfavorable eight-membered ring formation (Figure $1 \mathrm{C}$ ). Overall, this synthetic sequence can be formally seen as a rare case of enantioselective Pictet-Spengler reaction to achieve chiral medium-size nitrogen-containing polycyclic derivatives. ${ }^{[33]}$ It exploits the formation of a stable designed chiral hemiaminal (hemiaminal-masked reactive iminium ion) that overcomes the existing difficulties associated with the enantioselective acid-promoted version of this reaction. 
A.
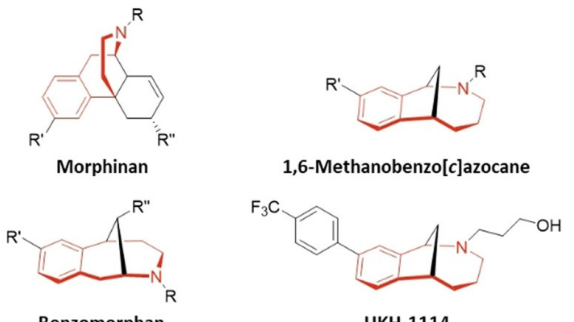

Benzomorphan

UKH-1114

B.
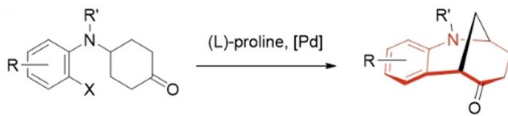

Jia

C.
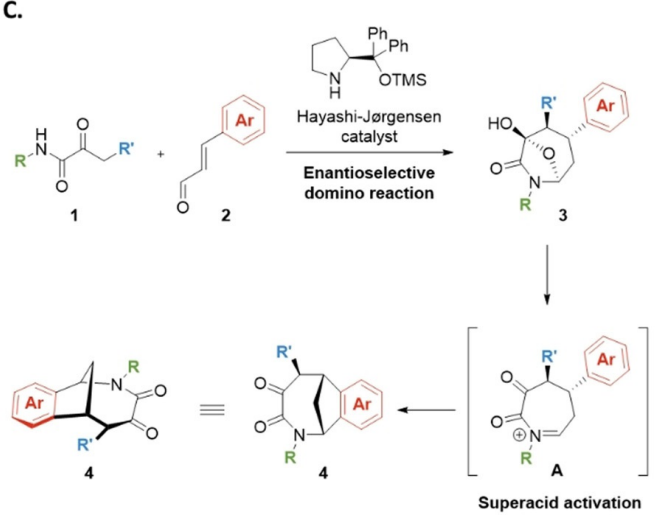

Figure 1. A) Naturally occurring bioactive morphinan alkaloids and related benzomorphans, 1,6-methanobenzo[c]azocane and sigma 2 receptor agonist UKH-1114. B) Reported synthesis of enantioenriched methylene-bridged benzazocanes analogues. C) Strategy for the enantioselective synthesis of methylene-bridged benzazocanes (this work).

\section{Results and Discussion}

$\mathrm{N}$-acyl iminium ions are highly reactive electrophiles that can be exploited for the synthesis of a range of diverse compounds. ${ }^{[34]}$ Activated by further complexation (or protonation) in triflic acid or hydrogen fluoride solutions, ${ }^{[35]}$ they can be intramolecularly and stereoselectively trapped by poor nucleophiles to generate chiral compounds in a concerted irreversible way. ${ }^{[36]}$ To test this hypothesis, the model substrate 3a was prepared from ketoamide $\mathbf{1 a}\left(\mathrm{R}=\mathrm{PMP}, \mathrm{R}^{\prime}=\right.$ $i \operatorname{Pr})$ and cinnamaldehyde $\mathbf{2}$ a with Hayashi-Jørgensen catalyst (see SI) and submitted to superacid conditions. A first try in $\mathrm{HF} / \mathrm{SbF}_{5}$ solutions led to a complex mixture (Table 1, entry 1 ). The reaction was then conducted in trifluoromethanesulfonic acid (TfOH) at $0^{\circ} \mathrm{C}$ and, to our delight, the expected chiral product $4 \mathbf{a}$ was formed in $66 \%$ yield with an enantiomeric excess exceeding $99 \%$ (Table 1, entry 2 ). Running the reaction at lower temperature resulted in a significant lower rate but did not improved the transformation (Table 1, entries 3-4). The yield could be further improved by running the reaction in dichloromethane as solvent with 50 equiv-
Table 1: Optimization of the superacid-promoted cyclization.

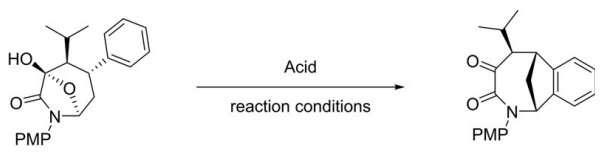

$3 a,>99 \%$ ee

$4 a>99 \%$ ee

\begin{tabular}{|c|c|c|c|c|}
\hline Entry & Acid & Solvent & Conditions & Yield [\%] ${ }^{[a]}$ \\
\hline 1 & $\mathrm{HF} / \mathrm{SbF}_{5}(7 / 1)^{[b]}$ & - & $-40^{\circ} \mathrm{C}, 0.5 \mathrm{~h}$ & $-[c]$ \\
\hline 2 & $\mathrm{TfOH}^{[b]}$ & - & $0^{\circ} \mathrm{C}, 0.5 \mathrm{~h}$ & $66(99)$ \\
\hline 3 & $\mathrm{TfOH}^{[b]}$ & - & $-20^{\circ} \mathrm{C}, 5 \mathrm{~h}$ & $64(78)^{[d]}$ \\
\hline 4 & $\mathrm{TfOH}^{[\mathrm{b}]}$ & - & $-20^{\circ} \mathrm{C}, 16 \mathrm{~h}$ & $66(99)$ \\
\hline 5 & TfOH (10 equiv) & $\mathrm{CH}_{2} \mathrm{Cl}_{2}$ & $0^{\circ} \mathrm{C}, 0.5 \mathrm{~h}$ & $L^{[\mathrm{e}]}$ \\
\hline 6 & TfOH (25 equiv) & $\mathrm{CH}_{2} \mathrm{Cl}_{2}$ & $0^{\circ} \mathrm{C}, 0.5 \mathrm{~h}$ & $40(77)^{[d]}$ \\
\hline 7 & TfOH (50 equiv) & $\mathrm{CH}_{2} \mathrm{Cl}_{2}$ & $0^{\circ} \mathrm{C}, 0.5 \mathrm{~h}$ & $87(90)^{[d]}$ \\
\hline 8 & TfOH (50 equiv) & $\mathrm{CH}_{2} \mathrm{Cl}_{2}$ & $0^{\circ} \mathrm{C}, 1 \mathrm{~h}$ & 90 (99) \\
\hline 9 & $\mathrm{Tf}_{2} \mathrm{NH}$ (25 equiv) & $\mathrm{CH}_{2} \mathrm{Cl}_{2}$ & $0^{\circ} \mathrm{C}, 0.5 \mathrm{~h}$ & $-[f]$ \\
\hline 10 & BNDHP (25 equiv) & $\mathrm{CH}_{2} \mathrm{Cl}_{2}$ & $0^{\circ} \mathrm{C}, 0.5 \mathrm{~h}$ & $-[\mp]$ \\
\hline 11 & $\mathrm{H}_{2} \mathrm{SO}_{4}(95 \%)^{[\mathrm{b}]}$ & - & $0^{\circ} \mathrm{C}, 0.5 \mathrm{~h}$ & $\_^{[e]}$ \\
\hline 12 & $\mathrm{TFA}^{[\mathrm{b}]}$ & - & $0^{\circ} \mathrm{C}, 0.5 \mathrm{~h}$ & $-[f]$ \\
\hline 13 & $\mathrm{Cu}(\mathrm{OTf})_{2}$ (2 equiv) & $\mathrm{CH}_{2} \mathrm{Cl}_{2}$ & $\mathrm{rt}, 16 \mathrm{~h}$ & $-^{[f]}$ \\
\hline 14 & $\mathrm{BF}_{3} \cdot \mathrm{Et}_{2} \mathrm{O}$ (2 equiv) & $\mathrm{CH}_{2} \mathrm{Cl}_{2}$ & $\mathrm{rt}, 16 \mathrm{~h}$ & $-[c]$ \\
\hline 15 & $\mathrm{AlCl}_{3}$ (2 equiv) & $\mathrm{CH}_{2} \mathrm{Cl}_{2}$ & $\mathrm{rt}, 16 \mathrm{~h}$ & $-[c]$ \\
\hline 16 & $\mathrm{FeCl}_{3}$ (2 equiv) & $\mathrm{CH}_{2} \mathrm{Cl}_{2}$ & $\mathrm{rt}, 16 \mathrm{~h}$ & $-[c]$ \\
\hline 17 & $\mathrm{FeCl}_{3}$ (50 equiv) & $\mathrm{CH}_{2} \mathrm{Cl}_{2}$ & $0^{\circ} \mathrm{C}, 1 \mathrm{~h}$ & $-[f]$ \\
\hline 18 & $\mathrm{FeCl}_{3}$ (50 equiv) & $\mathrm{CH}_{2} \mathrm{Cl}_{2}$ & $\mathrm{rt}, 16 \mathrm{~h}$ & $-[c]$ \\
\hline
\end{tabular}

[a] Isolated yield on $0.1 \mathrm{mmol}$ scale; conversion in brackets. [b] Used as solvent with a $0.05 \mathrm{M}$ concentration of substrate. [c] Complex mixture. [d] Determined by ${ }^{1} \mathrm{H}$ NMR analysis of the crude product using $p$ anisaldehyde as internal standard. [e] Low conversion. [f] Recovery of the starting material. BNDHP $=1,1^{\prime}$-binaphthyl-2,2'-diyl hydrogenphosphate. $\mathrm{PMP}=p$-methoxyphenyl. TFA $=$ trifluoroacetic acid

alents of $\mathrm{TfOH}$ (Table 1, entries 5-7). ${ }^{[37]}$ Increasing the reaction time to $1 \mathrm{~h}$ led to a full conversion and product $\mathbf{4 a}$ was obtained in $90 \%$ yield (Table 1, entry 8 ). The use of other strong Brønsted acids did not trigger the cyclization (entries 9,10 vs. entry 6). Decreasing the protonating ability of the system by running the reaction in sulfuric acid or trifluoroacetic acid was shown to be detrimental to the reaction, a result which supports our initial hypothesis and the necessity to use superacidic conditions to perform this reaction (Table 1, entries 11,12). This hypothesis was further reinforced by exploring the reactivity of $\mathbf{3} \mathbf{a}$ with Lewis acids. Using two equivalents of metal triflates or halides resulted in the recovery of the staring material or in a complex mixture (Table 1, entries 13-16). Any attempts with excess of Lewis acid (50 equivalents of $\mathrm{FeCl}_{3}$ ) did not allow to convert the model substrate 3a into the desired compound (Table 1, entries 17-18). ${ }^{[38]}$

The scope and functional group tolerance of this intramolecular Pictet-Spengler type benzannulation was next evaluated (Scheme 1). Ketoacetanilides $\mathbf{1 b}-\mathbf{d}$ yielded the desired chiral methylene-bridged benzazocanes $\mathbf{4} \mathbf{b}-\mathbf{d}$ in good yields with excellent enantioselectivity, confirming the great tolerance of this strategy toward aromatic amines. The benzylamine derivatives $\mathbf{1 e}-\mathbf{h}$ were also stereoselectively converted to the bicyclic derivatives $\mathbf{4} \mathbf{e}-\mathbf{h}$ in good yields and even in a preparative $1.25 \mathrm{~g}$ scale in the case of $\mathbf{4} \mathbf{f}$ without significant alteration of the efficiency. The ability to generate elaborated chiral methanobenzazocanones was also proven 


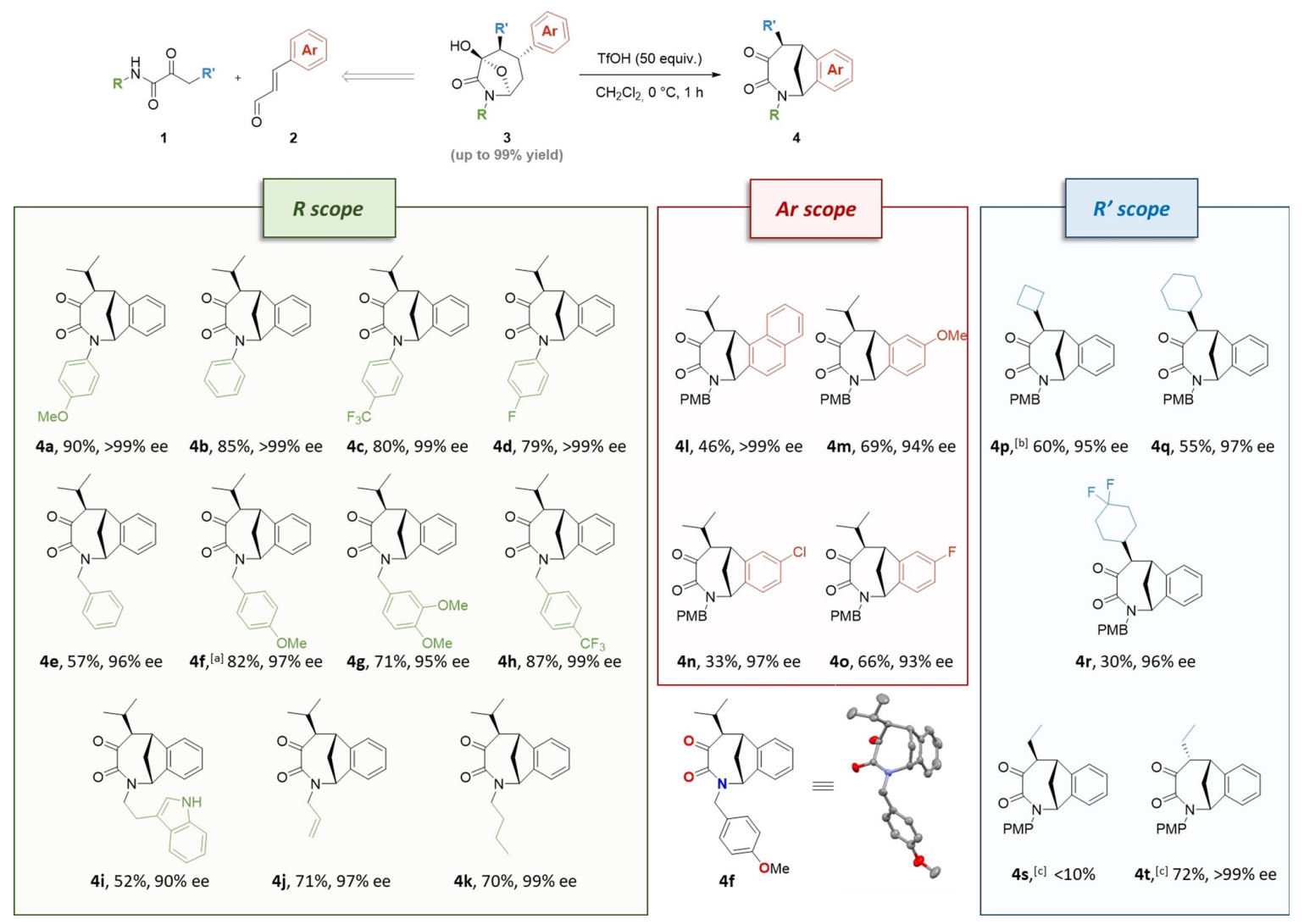

Scheme 1. Reaction scope for the synthesis of methylene-bridged benzazocanes. [a] Performed on $1.25 \mathrm{~g}$ scale. [b] The reaction time was extended to 6 hours. [c] The reaction was performed at room temperature for 4 hours. PMB $=p$-methoxybenzyl; PMP $=p$-methoxyphenyl.

by converting $\mathrm{N}$-substituted tryptamine substrate $\mathbf{1 i}$ to its bicyclic analogue $4 \mathbf{i}$ in reasonable yield and acceptable enantiomeric excess. The structure of these chiral compounds was also confirmed by X-ray analysis of the collected crystals of $\mathbf{4} \mathbf{f}$ generated after reaction of substrate $\mathbf{1}$. $^{[39]}$ Aliphatic ketoamides were also found to be compatible with these activation modes rendering products $\mathbf{4 j}$ and $\mathbf{4} \mathbf{k}$ in good yields and excellent enantiomeric excesses. The strategy was next applied to other aryl-substituted unsaturated aldehydes 11-o with success. While products $\mathbf{4 n , o}$ were generated in generally lower yields, their formation-which must involve the nucleophilic addition of the fluorinated and chlorinated deactivated aromatic rings-further reinforces the hypothesis of the transient formation of a highly reactive chiral cationic intermediate. Modification of the alkyl chain of the ketoamide by introducing cyclic substituents favored the formation of benzazocanones $\mathbf{4 p}$ and $\mathbf{4 q}$ bearing cyclobutyl or cyclohexyl exocyclic chain, respectively and a high-valued difluorinated analogue $\mathbf{4 r}$ was also synthesized with success. Surprisingly, substrate $3 \mathrm{~s}$ bearing an ethyl group proved to be reluctant to the superacidic activation and the expected bridged compound $4 \mathrm{~s}$ could only be characterized by ${ }^{1} \mathrm{H}$ NMR in the complex crude reaction mixture. Interestingly, the reactivity could be restored with the corresponding diastereomer $\mathbf{3 t}$ featuring an inverted stereocenter allowing the efficient formation of benzazocanone $\mathbf{4 t}$ with a perfect enantiomeric excess. This unexpected result highlights the potential of the proposed strategy to control the chirality of every stereocenter, offering the ability to generate series of chiral tridimensional benzomorphan related species.

The synthetic potential of these new elaborated species needed to be evaluated. To this end, PMB-protected product $4 \mathbf{f}$ was chosen as a model substrate to test further synthetic transformations (Scheme 2). A deprotection of this substrate in the presence of cerium ammonium nitrate allowed to generate a free amide 5 , prone to be further diversified by $\mathrm{N}$ alkylation. Methanobenzazocanone $\mathbf{4 f}$ could also be selectively converted to its thioamide $\mathbf{6}$ in good yield. Aminoketone 7 could be selectively synthesized by a sequential reduction/oxidation procedure. A methanobenzazocinol $\mathbf{8}$ (d.r. $>50: 1$ ), which contains four controlled stereocenters (three contiguous) could also be efficiently prepared after the diastereoselective reduction of the ketone $\mathbf{7}$ in the presence of sodium borohydride. Gratifyingly, the radical reduction of its xanthate analogue allowed for the synthesis of the methanobenzazocane 9, exhibiting the identical tricyclic structural core of antineuropathic drugs ${ }^{[27,28]}$ and further confirming the synthetic potential of the proposed strategy. 


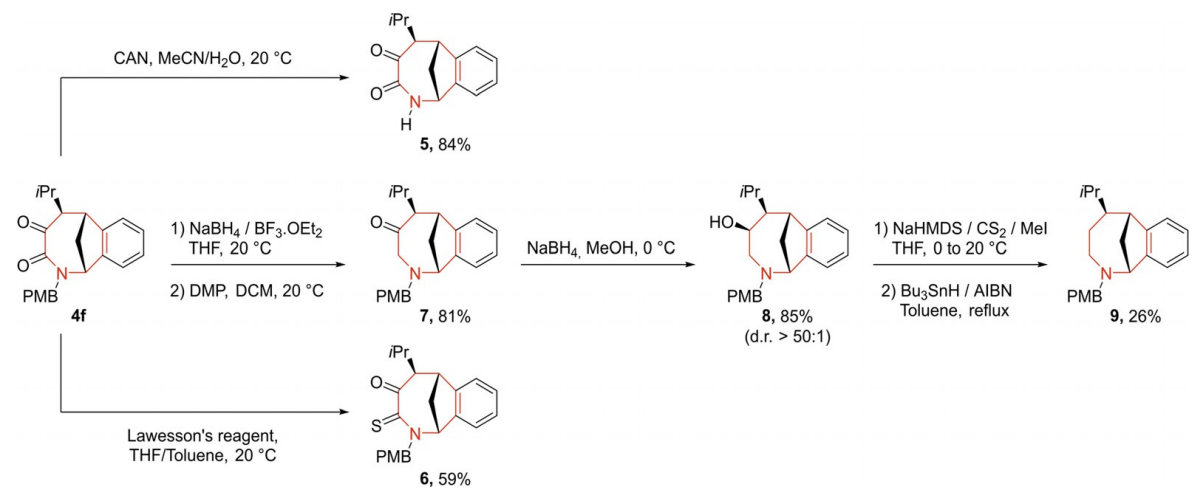

Scheme 2. Exploitation of $\mathbf{4} \mathrm{f}$ as a chiral high-valued synthetic platform to access diverse functionalized compounds.

To gain some mechanistic insights into the stereoselective formation of products $\mathbf{4}$ and explore the transient formation of a highly reactive $N$-acyl iminium ion, substrate $\mathbf{3} \mathbf{u}$ (d.r. $>20: 1,91 \% e e$, see $\mathrm{SI}$ ) behavior in neat superacid $\mathrm{TfOH}$ was examined by low-temperature NMR spectroscopy (Figure $2 \mathrm{~A})$.

Extensive NMR analysis of the crude reaction mixture resulting from the treatment of this substrate, for which any cationic trapping with the $o, o^{\prime}$-difluorinated aromatic ring must be avoided, provided strong evidence for the formation of the $N$-acyl iminium ion $\mathbf{A u}(\mathrm{C}-\mathrm{H}$ iminium proton at $\delta=$ $8.41 \mathrm{ppm}$ and $\mathrm{C}-\mathrm{H}$ carbon atom at $\delta=191.7 \mathrm{ppm}){ }^{[40]}$ This species is also characterized by an amide carbonyl group slightly deshielded to $172.5 \mathrm{ppm}$ in the ${ }^{13} \mathrm{C}$ NMR spectrum and a ketone carbonyl group slightly shielded to $195.8 \mathrm{ppm}$, respectively compared to an average of $167.5 \mathrm{ppm}$ and 202.5 ppm for products 4. In solution, ion Au is concomitantly generated with its precursor ion $\mathbf{B u}$ arising from substrate
A.

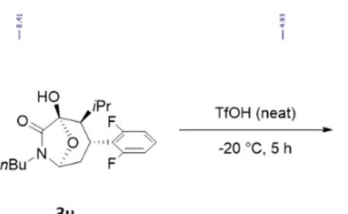

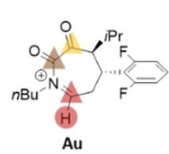

Au

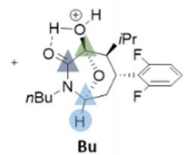

B.

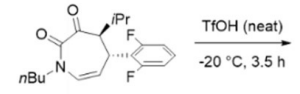

$10 u$

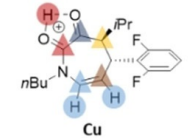

$\mathrm{Cu}$
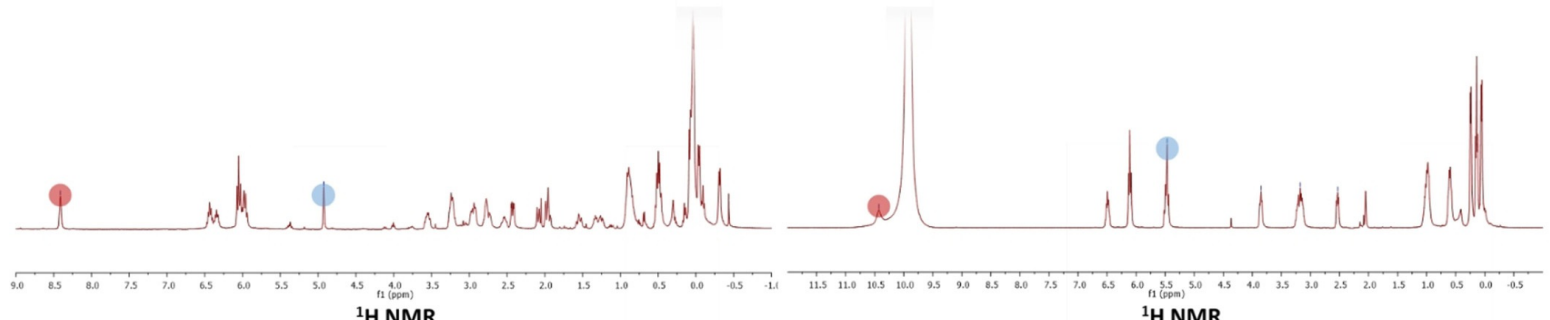
${ }^{1} \mathrm{H}$ NMR ${ }^{1} \mathrm{H}$ NMR
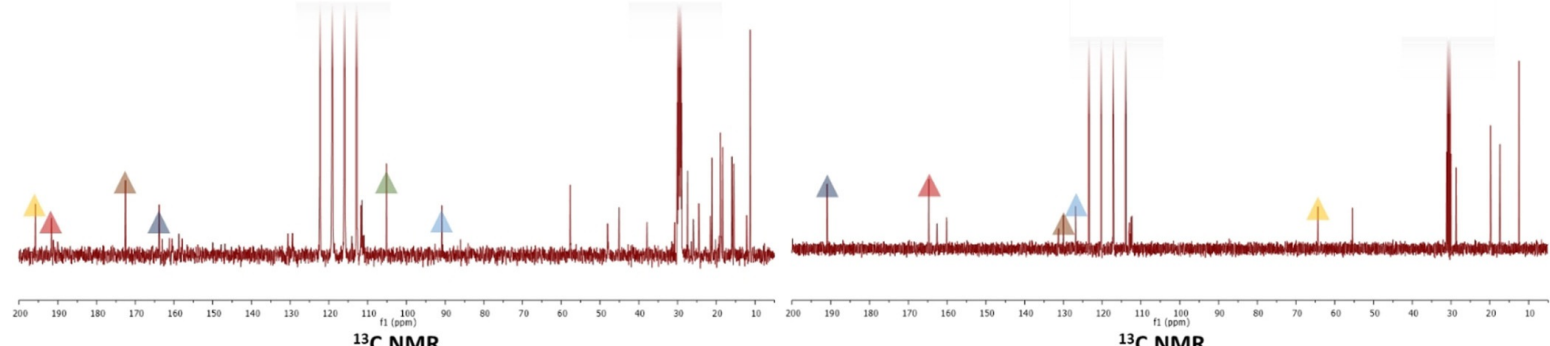

${ }^{13} \mathrm{C}$ NMR

${ }^{13} \mathrm{C}$ NMR

Figure 2. A) Low-temperature NMR evidence of the involvement of a transient highly reactive $\mathrm{N}$-acyl iminium ion species $\mathrm{Au}$ to favor the diastereoselective formation of methanobenzazocanes $4 ;{ }^{1} \mathrm{H}$ and ${ }^{13} \mathrm{C} \mathrm{NMR}$ spectra of a solution of substrate $3 \mathrm{u}$ in neat TfOH at $-20^{\circ} \mathrm{C}$. B) Generation and ${ }^{1} \mathrm{H}$ and ${ }^{13} \mathrm{C}$ NMR spectra of ion $\mathrm{Cu}$ generated in $\mathrm{TfOH}$ at $-20^{\circ} \mathrm{C}$, revealing the absence of formation of the $\mathrm{N}$-acyl iminium ion from enamide $10 \mathrm{u}$. 
protonation (Figure $2 \mathrm{~A}$ ). The $\mathrm{C}-\mathrm{H}$ signals attribution has been confirmed by DEPT analysis and ${ }^{1} \mathrm{H}^{-13} \mathrm{C}$ correlation shown by HSQC analysis (see SI). Interestingly, a similar analysis with $N$-butyl analogue of substrate $\mathbf{3}$ s revealed the absence of iminium ion formation at $-20^{\circ} \mathrm{C}$ (see SI). Even after prolonged reaction time and higher temperature (up to $20^{\circ} \mathrm{C}$ ) only traces of the targeted iminium ion of type $\mathbf{A}$ could be detected in situ. This confirms that the difference of reactivity between diastereomeric substrates $3 \mathrm{~s}$ and $\mathbf{3 t}$ can be directly related to the difficulty in generating the superelectrophilic iminium ion arguing for the observed formation of $4 \mathbf{t}$ over $4 \mathbf{s}$ (Scheme 1). These analyses prompted us to evaluate whether similar $N$-acyl iminium ion intermediates could be generated from the corresponding enamide.

To further explore this hypothesis, substrate $10 \mathbf{u}$ from phosphorus pentoxide dehydration of $\mathbf{3} \mathbf{u}{ }^{[41]}$ was submitted to superacid and its protonation scrutinized by using the same method. Surprisingly, even after prolonged reaction time, only one cationic species $\mathbf{C u}$ generated after amide protonation could be observed in the superacid solution of $10 \mathbf{u}$ at low temperature (Figure 2B). The structure of ion $\mathbf{C u}$ was confirmed by ${ }^{1} \mathrm{H},{ }^{13} \mathrm{C}$, DEPT and HSQC experiments (see SI). The difficulty to generate an activated $N$-acyl iminium ion Au from the seven-membered ketoenamide $10 \mathbf{u}$ could be tentatively correlated to the disfavored $\pi$ electron delocalization due to the conformational freedom of this seven-membered ring, also strongly influenced by the presence of the two contiguous carbonyl groups. ${ }^{[42]}$ Interestingly, this NMR study also revealed that for this type of ketoenamides, the electrophilic center must be the keto function which might be sufficiently electrophilic to be trapped by a pendent aryl substituent.

To explore this possibility, enantioenriched oxabridged azepanes $3 \mathbf{a}, \mathbf{c}, \mathbf{f}$ were converted to the corresponding azepane-2,3-diones 10. ${ }^{[41]}$ Submitted to superacid conditions (neat $\mathrm{TfOH},-20^{\circ} \mathrm{C}, 1 \mathrm{~h}$ ), the ketoenamides $\mathbf{1 0}$ were ideally converted into the targeted chiral methanobenzazocinols $\mathbf{1 1}$ with excellent yields and optimal stereoselectivities after chemoselective intramolecular trapping of the ketone function (Figure 3A). To summarize, following a three-step sequence (organocatalyzed enantioselective synthesis of aza-oxa-bicyclo[3.2.1] octane/phosphorus pentoxide-promoted dehydration/superacid-triggered cyclization), starting from simple readily available linear substrates, a new series of three-dimensional enantioenriched benzazocanes exhibiting three stereocenters including a quaternary hydroxylated one $^{[43]}$ could be directly and efficiently generated. Going one step further in complexity, we then explored a cascade cyclization process benefiting from the reactivity of both a transient $\mathrm{N}$-acyl iminium ion $\mathbf{A}$ and a superacid-activated ketoenamide intermediate C (Figure 3B). Starting from substrate $\mathbf{3 v}$ (d.r. 4:1), generated from ketoamide $\mathbf{1 v}$ and cinnamaldehyde (2a), the cascade cyclization led to the high diastereoselective formation of the polycyclic product $4 \mathbf{v}$ in $64 \%$ yield with no erosion of the enantiomeric excess. This pentacyclic compound exhibits five stereocenters (four contiguous ones and a chiral tertiary alcohol) in a rare 6/5/8 fused ring-sized molecular framework. With its excellent chemoand diastereoselectivity, this unprecedented cascade process
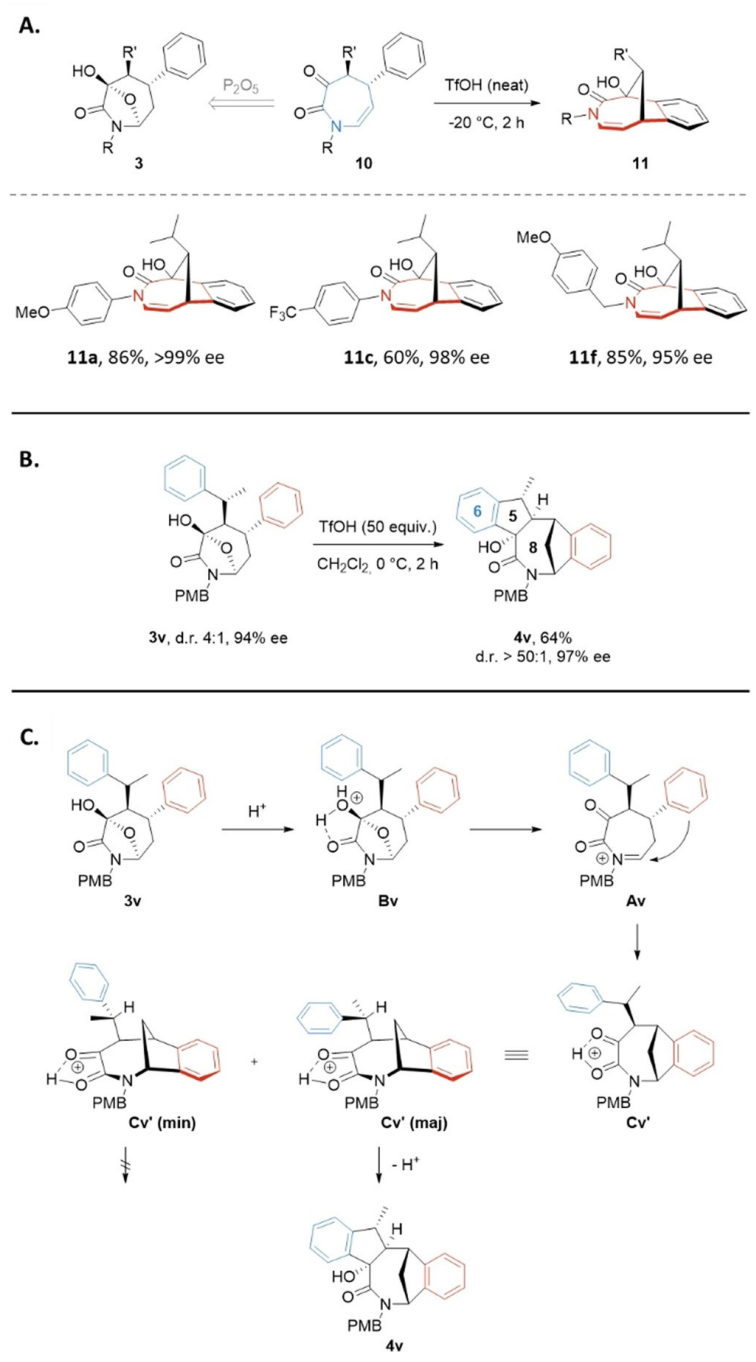

Figure 3. A) Sequential dehydration/superacid-promoted cyclization to generate bridged benzazocanes exhibiting a stereodefined tertiary alcohol. B) Superacid-promoted stereoselective cascade cyclization of substrate $\mathbf{3} \mathbf{v}$ and straightforward access to a pentacycle $4 \mathbf{v}(5$ controlled stereocenters including four contiguous ones). C) Suggested mechanism for the stereoselective formation of a single diastereomer $\mathbf{4} \mathbf{v}$ according to the previously demonstrated formation of ions $\mathbf{A}$ and $\mathbf{C}$.

opens up new synthetic perspectives for the generation of diversely functionalized chiral pentacyclic medium-sized ring systems.

The following mechanism could account for the exclusive formation of product $\mathbf{4 v}$ (Figure $3 \mathrm{C}$ ). Starting from $\mathbf{3 v}$, after activation in superacid, a mono protonated intermediate $\mathbf{B v}$ must be first generated. As demonstrated by low-temperature in situ NMR analysis, this ion $\mathbf{B v}$ is the precursor of the chiral $N$-acyl iminium ion Av whose superacid-enhanced electrophilic character must favor the cyclization process to generate a transient intermediate $\mathbf{C v}^{\prime}$. The subsequent superacid 
activation of this intermediate, ${ }^{[4]]}$ must drive the stereoselective polycyclization process to $\mathbf{4 v}$. Sterically-controlled by the presence of the methano bridge, only one diastereomer, for which a conformation placing the $\mathrm{H}$ group at the upper face of the bridged benzazocane $\left(\mathbf{C v}^{\prime}\right.$ maj), cyclizes to generate product $\mathbf{4 v}$ after aromatization. The intermediate $\mathbf{C v}^{\prime}$ min does not cyclize and the product resulting from its deprotonation after hydrolysis can be collected (see SI). This successful acid-mediated cascade brings this strategy one step further and extends the possibility of increasing the level of structural complexity of the formed nitrogen polycycles by simply introducing additional substituents on the linear ketoamide substrates.

\section{Conclusion}

In conclusion, previously used with great success in carbocation chemistry, superacid activation has now been associated to the organocatalysis field to produce unprecedented enantioenriched methylene-bridged molecules related to bioactive morphinans and benzomorphans. The ability to generate highly reactive chiral activated cations, which existence in these solutions has been demonstrated by lowtemperature NMR experiments, is now exploited to generate valuable elaborated new compounds. This formal enantioselective Pictet-Spengler reaction ${ }^{[33]}$ overcomes the existing difficulties associated with narrow substrate scope and limited nucleophiles, thereby offering a straightforward entry to enantioenriched bridged benzazocanes. We strongly believe that these results, disclosing the first association of organocatalysis and superacid chemistry, will contribute significantly to the progress in creating molecular diversity and complexity.

\section{Acknowledgements}

We gratefully acknowledge the Agence Nationale de la Recherche (project ANR-16-CE29-0005-01 - ORGASUP) for financial support and $\mathrm{PhD}$ and Post-doc grants (for Y.R., R.B., and B.M.). We also acknowledge support from the University of Poitiers, Aix-Marseille University, Ecole Centrale de Marseille, the Centre National de la Recherche Scientifique (CNRS), the European Union (ERDF), Région Nouvelle Aquitaine and the French Fluorine Network. We thank Dr. Nicolas Vanthuyne and Marion Jean (Aix-Marseille Université) for HPLC methods, and Dr. Michel Giorgi (www. spectropole.fr) for the X-ray structural analysis.

\section{Conflict of interest}

The authors declare no conflict of interest.

Keywords: acyliminium ion - benzazocane - organocatalysis . Pictet-Spengler · superelectrophile
How to cite: Angew. Chem. Int. Ed. 2020, 59, 1279-1285 Angew. Chem. 2020, 132, 1295-1301

[1] "The logic of chemical synthesis: Multistep synthesis of complex carbogenic molecules": E. J. Corey, Nobel Lecture December 8, 1990.

[2] D. C. Blakemore, L. Castro, I. Churcher, D. C. Rees, A. W Thomas, D. M. Wilson, A. Wood, Nat. Chem. 2018, 10, 383-394.

[3] C. J. Gerry, S. L. Schreiber, Nat. Rev. Drug. Discovery 2018, 17, $333-352$.

[4] D. G. Brown, J. Boström, J. Med. Chem. 2016, 59, 4443-4458.

[5] P. I. Dalko, Comprehensive enantioselective organocatalysis: Catalysts, reactions and applications, Wiley-VCH, Weinheim, 2013.

[6] I. Ojima, Catalytic asymmetric synthesis, Wiley, Hoboken, 2010.

[7] a) G. Bencivenni, L.-Y. Wu, A. Mazzanti, B. Giannichi, F. Pesciaioli, M.-P. Song, G. Bartoli, P. Melchiorre, Angew. Chem. Int. Ed. 2009, 48, 7200-7203; Angew. Chem. 2009, 121, 73367339; b) Z.-J. Jia, H. Jiang, J.-L. Li, B. Gschwend, Q.-Z. Li, X Yin, J. Grouleff, Y.-C. Chen, K. A. Jørgensen, J. Am. Chem. Soc. 2011, 133, 5053-5061; c) M. E. Abbasov, B. M. Hudson, D. J. Tantillo, D. Romo, J. Am. Chem. Soc. 2014, 136, 4492-4495; d) Y.-B. Wang, P. Yu, Z.-P. Zhou, J. Zhang, J. Wang, S.-H. Luo, Q.-S. Gu, K. N. Houk, B. Tan, Nat. Catal. 2019, 2, 504-513.

[8] a) J. Alemán, S. Cabrera, Chem. Soc. Rev. 2013, 42, 774-793; b) C. Grondal, M. Jeanty, D. Enders, Nat. Chem. 2010, 2, $167-$ 178; c) S. B. Jones, B. Simmons, A. Mastracchio, D. W. C. MacMillan, Nature 2011, 475, 183-188; d) H. Ishikawa, T. Suzuki, Y. Hayashi, Angew. Chem. Int. Ed. 2009, 48, 1304-1307; Angew. Chem. 2009, 121, 1330-1333.

[9] Z. Du, Z. Shao, Chem. Soc. Rev. 2013, 42, 1337-1378.

[10] For a seminal contribution, see: S. Mayer, B. List, Angew. Chem. Int. Ed. 2006, 45, 4193-4195; Angew. Chem. 2006, 118, 42994301.

[11] For a comprehensive overview about ion-pairing modes found in asymmetric catalysis, see: K. Brak, E. N. Jacobsen, Angew. Chem. Int. Ed. 2013, 52, 534-561; Angew. Chem. 2013, 125, 558 588.

[12] For a seminal contribution, see: T. D. Beeson, A. Mastracchio, J. B. Hong, K. Ashton, D. W. C. MacMillan, Science 2007, 316, $582-585$.

[13] For a recent example, see: A. G. Capacci, J. T. Malinowski, N. J. McAlpine, J. Kuhne, D. W. C. MacMillan, Nat. Chem. 2017, 9 , 1073-1077.

[14] For a review, see: M. Silvi, P. Melchiorre, Nature 2018, 554, 41 49.

[15] E. Zandvoort, E. M. Geertsema, B. J. Baas, W. J. Quax, G. J. Poelarends, Angew. Chem. Int. Ed. 2012, 51, 1240-1243; Angew. Chem. 2012, 124, 1266-1269.

[16] For a review, see: F. R. Bisogno, M. G. Lopez-Vidal, G. de Gonzalo, Adv. Synth. Catal. 2017, 359, 2026-2049.

[17] For a review with Brønsted acids, see: D. Parmar, E. Sugiono, S. Raja, M. Rueping, Chem. Rev. 2014, 114, 9047-9153.

[18] For a review with Lewis acids, see: A. Gualandi, L. Mengozzi, C. M. Wilson, P. G. Cozzi, Chem. Asian J. 2014, 9, 984-995.

[19] G. A. Olah, G. K. S. Prakash, A. Molnar, J. Sommer, Superacid Chemistry, Wiley, New York, 2009.

[20] R. R. Naredla, D. A. Klumpp, Chem. Rev. 2013, 113, 6905-6948.

[21] G. A. Olah, D. A. Klumpp, Superelectrophiles and their chemistry, Wiley, New-York, 2008.

[22] a) U. Castelli, J.-F. Lohier, I. Druckenmüller, A. Mingot, C. Bachman, C. Alayrac, J. Marrot, K. Stierstorfer, A. Kornath, A.C. Gaumont, S. Thibaudeau, Angew. Chem. Int. Ed. 2019, 58, 1355-1360; Angew. Chem. 2019, 131, 1369-1374; b) A. Martin, A. Arda, J. Désiré, A. Martin-Mingot, N. Probst, P. Sinaÿ, J. 
Jimenez-Barbero, S. Thibaudeau, Y. Blériot, Nat. Chem. 2016, 8 , $186-191$.

[23] J. Fahy, A. Duflos, J.-P. Ribet, J.-C. Jacquesy, C. Berrier, M.-P. Jouannetaud, F. Zunino, J. Am. Chem. Soc. 1997, 119, 85768577.

[24] H. Lachance, S. Wetzel, K. Kumar, H. Waldmann, J. Med. Chem. 2012, 55, 5989-6001.

[25] K. R. Campos, P. J. Coleman, J. C. Alvarez, S. D. Dreher, R. M. Garbaccio, N. K. Terret, R. D. Tillyer, M. D. Truppo, E. R. Parmee, Science 2019, 363, eaat0805.

[26] J. Kim, H. Kim, S. B. Park, J. Am. Chem. Soc. 2014, 136, 14629 14638.

[27] For the first synthesis and evidence of methanobenzazocane pharmacological effect, see: P. H. Mazzocchi, B. C. Stahly, J. Med. Chem. 1981, 24, 457-462.

[28] a) B. Yi, J. J. Sahn, P. M. Ardestani, A. K. Evans, L. L. Scott, J. Z. Chan, S. Iyer, A. Crisp, G. Zuniga, J. T. Pierce, S. F. Martin, M Shamloo, J. Neurochem. 2017, 140, $561-575$; b) J. J. Sahn, G. L. Mejia, P. R. Ray, S. F. Martin, T. J. Price, ACS Chem. Neurosci. 2017, 8, 1801-1811.

[29] G. Illuminati, L. Mandolini, Acc. Chem. Res. 1981, 14, 95-102.

[30] For one isolated example of a diastereoselective approach, see: M. Sainsbury, M. F. Mahon, C. S. Williams, A. Naylor, D. I. C. Scopes, Tetrahedron 1991, 47, 4195-4210.

[31] For the only reported enantioselective approach, see: R.-R. Liu B.-L. Li, J. Lu, C. Shen, J.-R. Gao, Y.-X. Jia, J. Am. Chem. Soc 2016, 138, 5198-5201.

[32] S. Goudedranche, D. Pierrot, T. Constantieux, D. Bonne, J. Rodriguez, Chem. Commun. 2014, 50, 15605-15608.

[33] a) J. Stöckigt, A. P. Antonchick, F. Wu, H. Waldmann, Angew. Chem. Int. Ed. 2011, 50, 8538-8564; Angew. Chem. 2011, 123 $8692-8719$; b) M. M. Heravi, V. Zadsirjan, M. Malmir, Mole- cules 2018, 23, 943/1-943/48; c) R. R. Nishanth, M. Barnali, C. Kaushik, ACS Comb. Sci. 2017, 19, 4199-4228.

[34] P. Wu, T. E. Nielsen, Chem. Rev. 2017, 117, $7811-7856$.

[35] a) R. R. Naredla, C. Zheng, S. O. N. Lill, D. A. Klumpp, J. Am Chem. Soc. 2011, 133, 13169-13175; b) S. Nakamura, H. Sugimoto, T. Ohwada, J. Am. Chem. Soc. 2007, 129, 1724-1732.

[36] A. Cousson, C. Gazeau, J.-P. Gesson, J.-C. Jacquesy, D Rambaud, B. Renoux, Bull. Soc. Chim. Fr. 1994, 131, 95-104.

[37] Carrying out the reaction in trichloroethanol (solvent used to prepare 3a) led to the recovery of the starting material. The development of a one-pot procedure to synthesize $4 \mathbf{a}$ from ketoamide 1a and cinnamaldehyde was therefore abandoned.

[38] Use of $\mathrm{TiCl}_{4}$ led to tetrahydropyrans, see: C. Sasso D'Elia, S. Goudedranche, T. Constantieux, M. Bella, D. Bonne, J. Rodriguez, Adv. Synth. Catal. 2017, 359, 3638-3641.

[39] CCDC 1921167 (4f) contains the supplementary crystallographic data for this paper. These data can be obtained free of charge from The Cambridge Crystallographic Data Centre.

[40] Y. Zhang, D. J. DeSchepper, T. M. Gilbert, K. K. S. Sai, D. A. Klumpp, Chem. Commun. 2007, 4032-4034.

[41] See the Supporting Information for more details

[42] K. Gopalaiah, H. B. Kagan, Chem. Rev. 2011, 111, 4599-4657.

[43] Y. Liu, S.-J. Han, W.-B. Liu, B. M. Stoltz, Acc. Chem. Res. 2015 $48,740-751$.

[44] K. K. S. Sai, P. M. Esteves, E. Tanoue da Penha, D. A. Klumpp, J. Org. Chem. 2008, 73, 6506-6512. 